\title{
INTERNATIONAL PUBLICATIONS: TIPS FOR AUTHORS
}

Ongoing advances in technology has allowed our world to become smaller and has provided us with unprecedented opportunities to connect and collaborate with our nurse colleagues around the globe. Through these newly acquired collaborations, we have come to recognize that we share many common issues in the practice of nursing, education, and research. Our cultural similarities and differences enhance our understanding of these commonalities and uniqueness. As we continue our efforts to build the scientific base for nursing, our responsibility to communicate those efforts becomes increasingly important. To that end, we must be committed to publishing our findings in both national and international journals. Standards exists for international publications, ${ }^{1}$ but in this editorial, I would like to share with you some thoughts, reflections, and experiences on publishing both in national and in international journals.

One of the initial considerations in publishing your work is to decide which journal best suits the paper. Many articles are written that detail the steps in deciding where to publish. Within an individual country, the priority issues for healthcare are reflected in the type of article journals publish. For example, in the U. S. a priority healthcare issue is quality and safety in relation to patient outcomes and so these types of articles are evident in many types of journals. When making a determination about an appropriate journal to publish in, ask the following questions. Does the journal have an interest in your topic? Some strategies to determine the answer to this question is to first read the author guidelines which typically include the type of articles the journal is willing to publish. Look through the last several years of the journal to assess what topics are of interest. Is there a paper that was recently published that is similar to yours? If so, the journal may or may not want to publish a similar paper. Determine the scope of your paper and if it is consistent with the journal's scope. In my experience, editors are willing to provide advice on whether your article is a 'fit' with the journal.

Another fundamental aspect in determining the type of journal to publish your work is to reflect on the target audience and the readership of the journal. For instance, if you are publishing an article on governance, who is it important for? Administrators? Practitioners? Researchers? Which leads to the ever important question on how relevant is the impact factor of the journal. Certainly impact factor, which is a quantitative assessment of the quality of the journal and its impact on science, ${ }^{2}$ is a critical consideration, particularly if you are an academic whose career is tied to tenure and promotion. Although journal impact factors are necessary, also consider whether publishing in a journal will lead to an impact that will advance our professional practice. In my experience, the research I have conducted on delegation was useful to the practice of delegation.

Selecting a journal also includes its reputation in publishing high quality articles. If the journal has a good reputation, it is probable you will receive a high quality peer review of your manuscript. Even if the manuscript is rejected, the quality of the review will be important in finding a 'home' for your manuscript. Consider the time in review and the time to publication. How quickly should your findings be in the public domain? One option for many journals that have a long manuscript acceptance to publication time, is for the manuscript to be epublished ahead of print. Epub ahead of print has the benefit of findings being available electronically before the print version is available. Lastly, the cardinal rule for publishing is to follow the author guidelines in preparing your manuscript. Not following guidelines will not result in a positive or timely outcome.

Once you have selected the journal to submit your manuscript, the second area to consider in international publications is the actual writing of the manuscript. The importance of a well written abstract and introduction cannot be overstated. Be clear and precise in describing the problem and why it is important. Be sure to address its significance! A simple question to ask of your manuscript is "why does this matter?" "Why would anyone want to read this manuscript?" How will it improve care?. ${ }^{3}$ If you are seeking to publish findings from a study from a country that may not have the same level of evidence that is found in other countries, be sure to highlight the contribution to science. Science and knowledge development does not have borders and so the more explicit your can be about its contribution to nursing and healthcare, the better the chances are for publication.

In writing your manuscript, include all the elements of a rigorous scientific study and described in scientific terms. Reading similar articles from the journal you intend to publish in will guide which elements are a 'must' to include. If you are new to publishing in general, be careful not to 'data dump' which is reporting on all the data in that you have collected. Data dumping can detract from the precision and significance of the study. As important as the introduction is, the discussion is likewise critical. Don't repeat results, summarize and put your findings in the context of the literature. This is an opportunity for you to describe what your study added to the body of knowledge. The discussion is a good place for you to speculate about the meaning of your findings without going beyond the data.

Publishing in an international journal may often mean you need to translate your manuscript into the native language of the journal. Translation can be a daunting task. Even if it is professionally translated, have a native speaking person read it. Translations can be literal but can lack the content and cultural semantic equivalence. A native speaking person can more easily detect common grammatical and syntactical errors.

A few additional tips on publishing to keep in mind. Often an author has an opportunity to present their work at conferences which can be a productive forum to obtain feedback, to stimulate your thinking on what your findings mean. 
So present your work whenever you can prior to publishing. Remember the ethical guidelines in publishing regarding plagiarism, self-plagiarism and duplication. To avoid plagiarism when discussing other author's work, be sure to cite appropriately. Lastly self-plagiarism is likewise an ethical error that can be made. If you are publishing several articles from one study, remember that if you are using similar words or thoughts that have been previously published, you must cite the previously published article. Once your article is published, it is copyrighted by the journal. Resources, such as the $\mathrm{APA}^{4}$ and publishing best practices ${ }^{5}$ are available to guide you.

After you have submitted your manuscript, you are left to wait for a decision. The editor will typically read the manuscript and assign it to 2-3 blinded peer reviewers. Each reviewer will provide the editor with a review and a recommendation which usually ranges from accepting to major revisions and re-review to rejection. If your manuscript was accepted on the first submission, Kudos to you! If the recommendation is to revise and resubmit, do it in a timely way. Thank reviewers for their comments and respond to each point. Good reviewers take time and thought to review the manuscript and want you to be successful. If you manuscript is rejected, read the review carefully and find another journal that might be a better fit.

In my experience as a reviewer of international authors, I have found several challenges that detract from the scientific review of the manuscript. For example, the importance of the research and contribution to science is often underdeveloped. Likewise, the abstract, which provides the initial lens into the manuscript ${ }^{3}$ for the reviewer, is often brief and not well described. The importance of a well written and clear abstract is essential for all authors but may pose additional challenges for international authors. As I mentioned, the description of the problem and the significance is a key attribute of a quality manuscript.

A good quality translation facilitates the review of the merits of the scientific contribution. When the grammar and formatting is poor, it is difficult to focus on the content. The inclusion of tables is often helpful if the tables are clear and well-constructed. In my experience, tables are sometimes unclear and not appropriately formatted to the journal specifications. In reviewing a manuscript from an international author, a reviewer is unlikely to be familiar with the norms and cultural idioms. For example, in the U. S., when we talk about decision making, we say we will 'make a decision'. In many other countries, this is often said as we will 'take a decision'. As a reviewer, changes in the phrasing may not be well known and so having a native speaking person review your manuscript prior to submission is helpful.

In conclusion, for one month, I have had the wonderful opportunity to work with my Brazilian nurse colleagues at the UFSC. As a result of this experience, I have emerged with a deepened appreciation of our common interests, similarities, and differences that make the mandate for international publications critical. Obrigada.

\section{REFERENCES}

1. Wager E, Kleinert S. Responsible research publication: international standards for authors. A position statement developed at the $2^{\text {nd }}$ World Conference on Research Integrity, Singapore [online], July 22-24, 2010. In: Mayer T, Steneck N, eds. Promoting research integrity in a global environment (pp.309-316). Singapore: Imperial College Press/World Scientific Publishing. 2011. Retrieved from: http://www.oeawi.at/downloads/International\%20 standards_authors_for\%20website_11_Nov_2011.pdf

2. Dong P, Loh M, Mondry A. The "impact factor" revisited. Biomed Digit Libr. 2005 Dec; 2(7).

3. Nahata MC. Tips for writing and publishing an article. Annals of Phamacotherapy. 2008 Feb; 42(2):273-7.

4. American Psychological Association. The publication manual of the American Psychological Association. $6^{\text {th }}$ ed. Washington (US): Author; 2010.

5. Graf C, Wager E, Bowman A, Fiack S, Scott-Lichter D, Robinson A. Best practice guidelines on publication ethics: a publisher's perspective. Int J Clin Pract. 2007 Jan; 61(Suppl 152):1-26.

Mary Kathleen Anthony

Ph.D., RN, CS, Professor, Associate Dean Research at College of Nursing Kent State University, Ohio, United States 